\title{
DIFFERENCE BETWEEN USING COLOURIMETRIC VALUES (L*A*B*) OR OPTICAL DENSITY FOR RANDOM PRINT NONUNIFORMITY QUANTIFICATION
}

\author{
Ivana Jurič (D), Dragoljub Novaković (D), Ivana Tomić (D), Ana Lilić (D), Željko Zeljković \\ University of Novi Sad, Faculty of Technical Sciences, \\ Department of Graphic Engineering and Design, Novi Sad, Serbia
}

\begin{abstract}
Surface nonuniformity can appear at a print in two forms: random or as a systematic variation. Both types appear in digital printing, but in this study, an only random variation on the digital prints was analyzed. We used two methods for quantification of the nonuniformity: M Score and ISO methods, which are based on physical measurement of the prints, using one of the measuring instruments that measure the colourimetric ( $L^{*} a^{*} b^{*}$ values) and densitometric (optical density) values. Samples used in this paper were generated using the software MATLAB - Macro Uniformity Toolbox add-in that is printed on the same paper using ink jet printing machine Epson Stylus PRO 7800. We used spectrophotometer Eye One Pro2 and software Measure Tool to measure samples. Other calculations are done in a software application in Microsoft Excel. Based on the results obtained in the research, it is concluded that both methods can be used to measure the random variation of the print nonuniformity.
\end{abstract}

Key words: random print nonuniformity, M Score, optical density, digital printing

\section{INTRODUCTION}

In the reviewed literature (Petersson, 2005; Christoffersson, 2004; Fahlcrantz, 2005; Sadovnikov et al, 2007; Weingerl et al, 2014; Rasmussen et al, 2006), there are several different definitions of print (non)uniformity. The general physical definition would be that the print nonuniformity is an unwanted variation of optical density (reflected light) from the print. Different types of print nonuniformity are presented in Figure 1. Two main groups are random and systematic nonuniformity.

a)

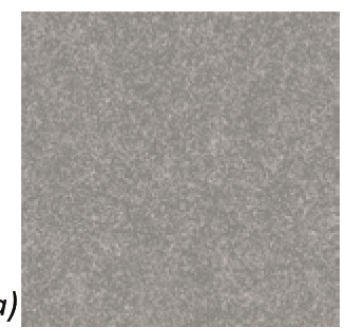

b)

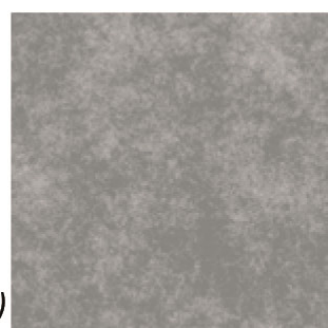

c)

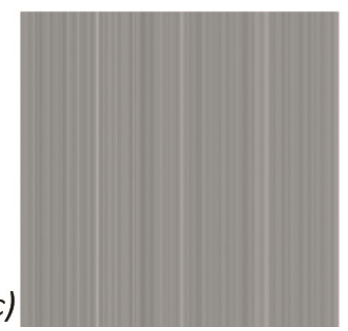

d)

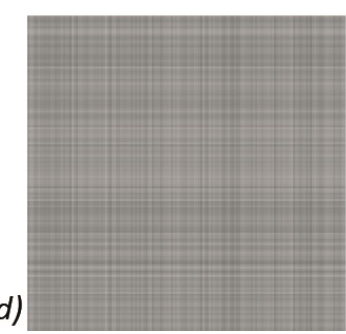

Figure 1: Different types of print nonuniformity: a) small-scale (graininess), b) large-scale (print mottle) random nonuniformity, c) stripes and d) wire mark texture - as systematic nonuniformity (Christoffersson, 2004)

In this paper, we only analyzed one type od print nonuniformity - random print nonuniformity. Print nonuniformity could be quantified using different methods: NU index (Rilovski, 2012), GLCM method (Hladnik et al, 2011; Jurič et al, 2015), standard ISO 13660, the method by (Christoffersson, 2004), etc. Common to all methods is that they are based on the Print Quality Analysis method. There is also a method based on the spectrophotometric measurements, and it is called M Score method.

The M Score method is based on spectrophotometric measurement and the analysis of the colourimetric values ( $L^{*} \mathrm{a}^{*} \mathrm{~b} *$ values) and calculating $\Delta \mathrm{E}$ colour differences, based on which one value is obtained in the range of 100 (uniform) to 0 (nonuniform) which determines the uniformity of the printing. Kraushaar described this method within the Fogra standard (Kraushaar, 2010). It is recommended that the test chart should be printed on the A3 format. After printing the test field should be divided into 46 columns and 59 rows, giving a tile of the size $6 \times 6 \mathrm{~mm}$. For each tile, L*a*b* values are measured. Then, for each row and each column, the mean $L^{*} a^{*} b^{*}$ value is calculated, and then the colour difference between the rows and between the columns is calculated, using $\Delta \mathrm{E}_{00}$ or $\Delta \mathrm{E}_{76}$ formula. According to these measured colour differences, M Score value is calculated. A detailed procedure for this method is shown in the paper (Jurič, 2018). 
In this paper, we used two methods for print nonuniformity assessment: M Score and ISO 13660 method (the measured value of optical density was used for the ISO method, not as Print Quality Analysis).

\section{MATERIALS AND METHODS}

Samples used in this paper were generated using the software MATLAB - Macro Uniformity Toolbox (Rawashdeh, 2006), which is intended for simulation of surface nonuniformity in the printing process which was used in the paper (Rasmussen et al, 2006). In this add-in, it is possible to vary several parameters. For this research, only the amplitude $(A)$ of the blothces was varied. On all samples, the background (base) colour is neutral gray (0.5) (Fahlcrantz, 2005; Lindberg et al, 2005), and the size of digital samples is $N=2048$ px. For the simulation of random variation of nonuniformity, the function RN.m (RN - Random noise) was used. The size of the blotches is defined by two values - $p_{\min }$ and $p_{\max }$, which represent the maximum and minimum frequency. Both values were unchanged and amounted to $p_{\min }=20$, and $p_{\max }=100$. A different error level is achieved by varying the amplitude:

$$
A=0,0.003,0.006,0.00975,0.017,0.026,0.0496,0.059,0.074,0.092,0.13,0.18
$$

Simulated samples were printed at $160 \times 160 \mathrm{~mm}$. The selected printing technique for preparing samples was ink jet since based on previous research (Lindberg et al, 2005), it was concluded that prints obtained by ink jet printing were more uniform than those obtained by electrophotography.

The samples were printed on the Epson Stylus PRO 7800 digital ink jet machine. The machine settings were as follows: Paper - Single weighted Matte Paper, Print mode - Color I Profile - Epson Standard (sRGB). All samples were printed on uncoated paper IQ selection whiteboard $\left(250 \mathrm{~g} / \mathrm{m}^{2}\right)$.

Test chart of $160 \times 160 \mathrm{~mm}$ was divided into 20 rows and 20 columns, so in this case, the measuring tile was slightly larger $(8 \times 8 \mathrm{~mm})$. Samples were measured using the spectrophotometer - Eye One Pro2 and the Measure Tool software. The M Score value was calculated in a software application developed in Excel (Jurič, 2018). Both formulae $\left(\Delta E_{76}\right.$ and $\left.\Delta E_{00}\right)$ were used to calculate colour differences to check if there is a difference between them.

In addition to the M Score method, nonuniformity was measured using the optical density of the samples, more precisely based on the standard deviation of the measured optical density values for all tiles within a single sample. This method is similar to that described in ISO 13660 standard. Standard ISO 13660:2001 defines the methods and procedures for measuring different secondary quality attributes, as well as the print nonuniformity of monochromatic prints. The standard describes only one type of nonuniformity - random variations, which, depending on the frequency of the optical density variation, may be high - which is defined as graininess, or low - which is defined as mottling. Mottling represents macro-uniqueness and is defined as "aperiodic variation of optical density in all directions at frequencies smaller than 0.4 cycles $/ \mathrm{mm}^{\prime}$ (ISO, 2001). Mottling represents the standard deviation of optical density measurement.

\section{RESULTS AND DISCUSSION}

Results of print nonuniformity obtained with M Score method are presented in Figure 2. By changing the amplitude of the blotches, the M Score value is also changed. By increasing the amplitude (A), surface nonuniformity increases and the M Score values decreases. The sample S1 that is uniform has the highest $M$ Score value ( 84.81 for $\Delta E_{76}$ and 85.67 for $\Delta E_{00}$ ). The $M$ Score gradually decreases, except that values for samples S3 and S4 are very similar, even for S4 slightly higher ( $\Delta E_{76}=71.04$ and 72.67 , respectively). The same was observed for samples S7 and $\mathrm{S} 8\left(\Delta \mathrm{E}_{76}=29.64\right.$ and 29.44 , respectively).

For each tile within a single sample, the optical density was measured based on which the average and standard deviation were calculated. The results are shown in Table 1 and Figure 3. Based on the results, it can be noticed that the average optical density is almost identical for all samples, while the standard deviation increases as the amplitude of blothces increases. So standard deviation of optical density could be used as a measure for the quantification of random nonuniformity. 


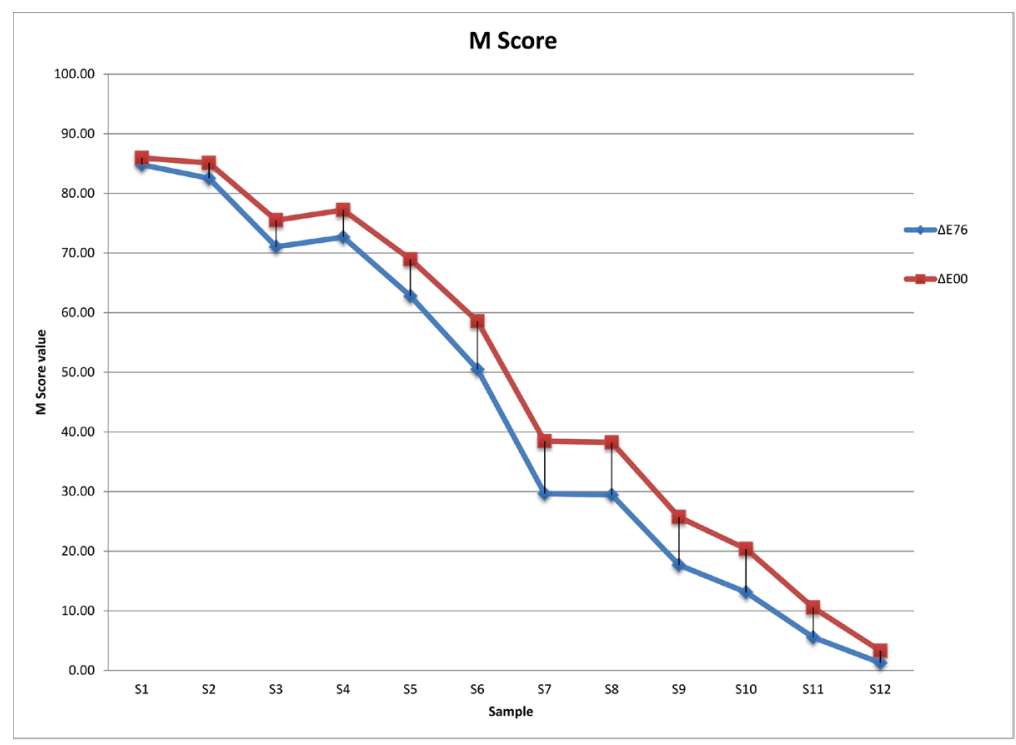

Figure 2: Obtained results of nonuniformity using M Score method

Table 1: Results of nonuniformity obtained using optical density (average D and standard deviation)

\begin{tabular}{|c|c|c|c|c|c|c|c|c|c|c|c|c|}
\cline { 2 - 13 } \multicolumn{1}{c|}{} & S1 & S2 & S3 & S4 & S5 & S6 & S7 & S8 & S9 & S10 & S11 & S12 \\
\hline Average D & 0.387 & 0.385 & 0.384 & 0.387 & 0.384 & 0.386 & 0.385 & 0.386 & 0.386 & 0.383 & 0.382 & 0.389 \\
\hline Std & 0.003 & 0.004 & 0.007 & 0.008 & 0.013 & 0.019 & 0.035 & 0.041 & 0.054 & 0.064 & 0.089 & 0.130 \\
\hline
\end{tabular}

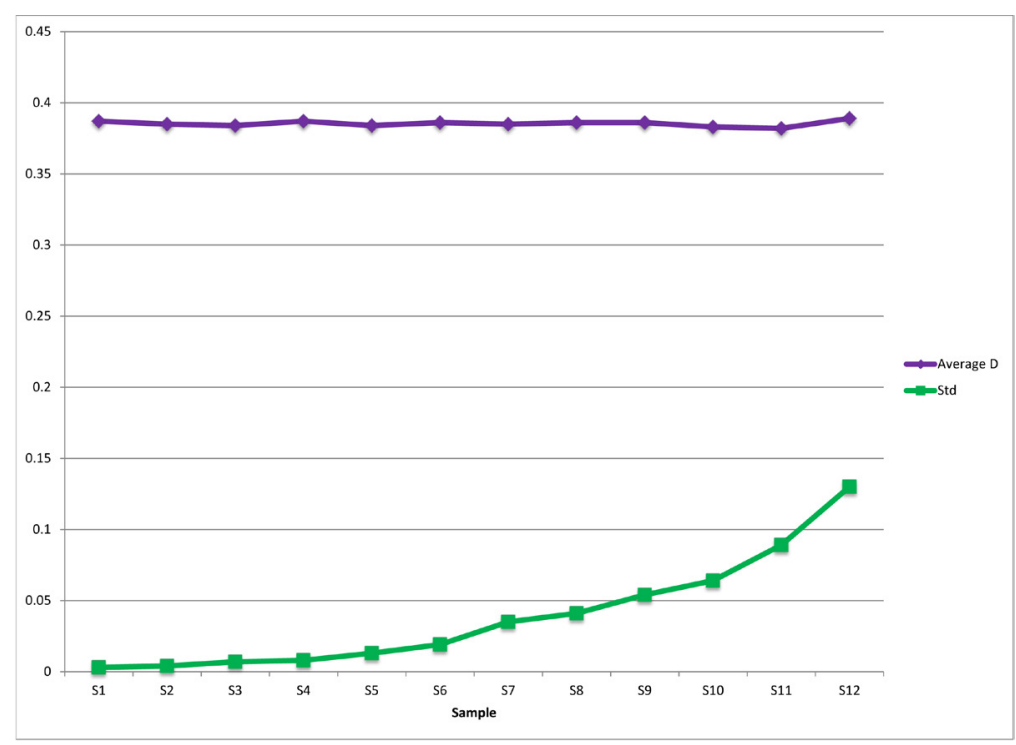

Figure 3: Obtained results of nonuniformity using optical density (average D and standard deviation)

\section{CONCLUSIONS}

As already mentioned, surface nonuniformity can be measured using different methods. Some methods are adapted for random measurement and some for measuring systematic variation. This paper examines the possibility of using two methods based on the measurement of the colourimetric coordinates $\left(L^{*} a * b *\right.$ values) and the optical density of the field. Based on the obtained results, it can be concluded that both are suitable for measuring random variation. It is important to note that both methods are suitable when measuring a smaller test field because it is time-consuming if there is no automatic measuring instrument 
for measuring the colourimetric coordinates ( $\mathrm{L}^{*} \mathrm{a}^{*} \mathrm{~b}^{*}$ values) and the optical density. In the case of larger fields, methods based on Print Quality Analysis are more convenient for use.

\section{ACKNOWLEDGMENTS}

This work was supported by the Serbian Ministry of Science and Technological Development, Grant No.: 35027 "The development of software model for improvement of knowledge and production in graphic arts industry."

\section{REFERENCES}

[1] Christoffersson, J.: "Evaluation of Systematic \& Colour Print Mottle", MSc Thesis, Linkopings Universitet, 2004.

[2] Fahlcrantz, C. M.: "On the evaluation of print mottle", PhD thesis, Stockholm University, 2005.

[3] Hladnik, A., Mihael, L.: "Paper and board surface roughness characterisation using laser profilometry and gray level co-occurrence matrix", Nordic Pulp and Paper Research Journal 26(1), 99-105, 2011.

[4] International Organization for Standardization (ISO), ISO/IEC 13660: 2001 Information Technology Office Equipment - Measurement of image quality attributes - Binary Monochrome text and graphic images, International Organization for Standardisation and International Electrotechnical Commission, 2001.

[5] Jurič, I., Karlović, I., Novaković, D., Tomić, I.: "Comparative study of different methods for the assessment of print mottle", Color Research and Application 41(5), 493-499, 2015. doi:10.1002/col.21984.

[6] Jurič, I.: "Model za kontrolu površinske uniformnosti digitlanih otisaka", PhD thesis, University of Novi Sad, 2018.

[7] Kraushaar, A.: "Evaluation of within sheet uniformity by means of M-Score", Fogra, 2010, URL: http://www.fogra.org/index.php?menuid=263\&downloadid=138\& reporeid=206 (last request 2016-02-17).

[8] Lindberg, S., Fahlcrantz, C. M.: "Perceptual assessment of simulated print noise with random and periodic structure", Journal of Visual Communication and Image Representation, 16(3), 271-287, 2005. doi: 10.1016/j.jvcir.2004.11.002.

[9] Petersson, J.: "A Review of Perceptual Image Quality", Independent thesis Basic level, Linköping University, 2005.

[10] Rasmussen, D.R., Donohue, K.D., Ng, Y.S., Kress, W.C., Gaykema, F., Zoltner, S.: "ISO 19751 macrouniformity", Proceedings of Electronic Imaging 2006, (San Jose, California, USA, 2006), doi:10.1117/12.648086.

[11] Rawashdeh, N.: "Macro Uniformity Toolbox (v2)", 2006, URL: https://www.mathworks.com/matlabcentral/fileexchange/9882-macro-uniformity-toolbox--v2?requestedDomain=true (last request: 2016-01-04).

[12] Rilovski, I.: "Influence of paper surface properties and toner type on digital print mottle", Celuloza Si Hartie 61, 4-9, 2012.

[13] Sadovnikov, A., Lensu, L., Kälviäinen, H.: “Automated Mottling Assessment of Colored Printed Areas", Proceedings of 15th Scandinavian Conference on Image Analysis, (Springer, Berlin, Heidelberg, 2007), pages 621-630.

[14] Weingerl, P., Hladnik, A.: "Objective methods for print inhomogeneity evaluation and their correlation with visual perception", Journal of Imaging Science and Technology 62(1), 2014 doi: 10.2352/J.ImagingSci.Technol.2018.62.1.010502.

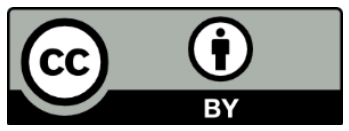

(C) 2018 Authors. Published by the University of Novi Sad, Faculty of Technical Sciences, Department of Graphic Engineering and Design. This article is an open access article distributed under the terms and conditions of the Creative Commons Attribution license 3.0 Serbia (http://creativecommons.org/licenses/by/3.0/rs/). 